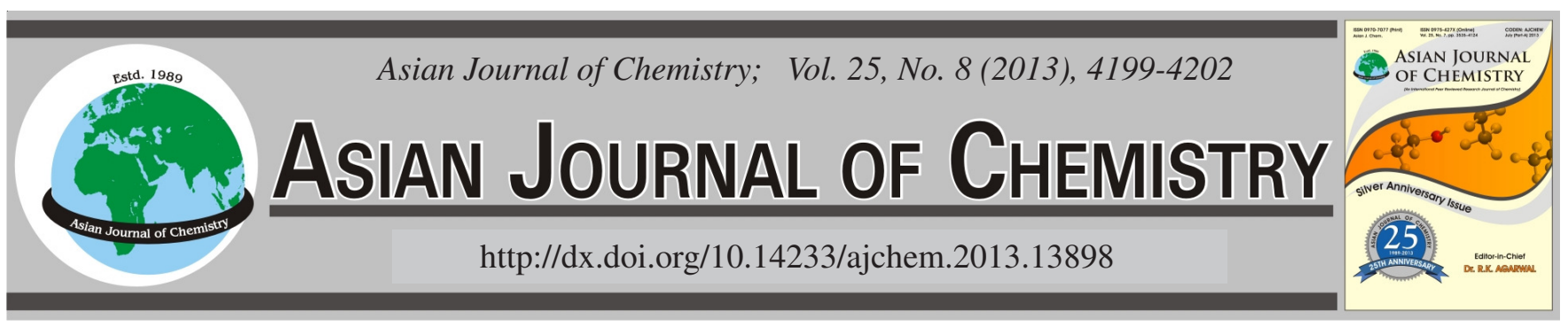

\title{
Heavy Metal Contamination in a Soil-Rice Ecosystem in the Vicinity of Abandoned Rural Unsanitary Landfill
}

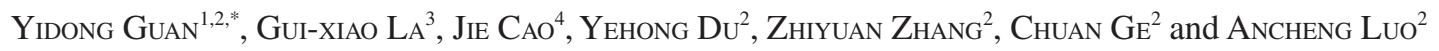

\begin{abstract}
${ }^{1}$ School of Environmental Science and Engineering, Nanjing University of Information Science and Technology, Nanjing 210044, P.R. China ${ }^{2}$ College of Environmental and Resource Sciences, Zhejiang University, Hangzhou 310029, P.R. China ${ }^{3}$ Industrial Crop Research Institute, Henan Academy of Agricultural Sciences, Zhengzhou 450002, P.R. China

${ }^{4}$ Shaoxing Company of Zhejiang Tobacco Company, Shaoxing 312000, P.R. China
\end{abstract}

*Corresponding author: E-mail: yidongguan@163.com

\begin{abstract}
The ecosystem adjacent to the abandoned rural unsanitary landfill has been contaminated. The soil cadmium was higher than the maximum allowable content of agricultural soil. There was a remarkable bioaccumulation trend of heavy metals in the rice organs. Chromium and lead contents in rice grain were much higher than the threshold levels, 2.9-6.7 folds and 1.0-1.5 folds of the legislation limits, respectively. Linear correlation analysis showed that the slightly alkaline leachate from the unsanitary landfill was one of the main factors causing the higher soil $\mathrm{pH}$ and then affecting the absorption of rice on the cadmium.

Key Words: Rural unsanitary landfill, Heavy metals, Soil, Rice, Leachate.
\end{abstract}

\section{INTRODUCTION}

Rural waste is combined solid waste in rural residents' daily life. After 1990, the components of rural waste changed remarkably as well, parts of hazardous and industrial wastes were commingled into these sites due to the rapid development of township enterprises and the lack of effective administration. Rural waste is no longer to be one favorable agricultural fertilizer. Because of the giant imbalance between the shrinking resource utilization approach and the increasing production of the rural waste, large amounts of rural waste accumulated in the countryside. It is estimated that there were over one hundred million tons of rural waste which were abandoned in rural areas of China each year (http://www.china.com.cn/zhibo/ 2008-02/18/content_10048366.htm). In such conditions, almost each village constructed one or two unsanitary landfills to dispose these rural wastes. After 2000s, those sites were replaced with the standardized municipal landfills, and were gradually closed and abandoned. However, our field investigation proved that the unsanitary landfills still discharged the contaminants, especially leachate to the environment continuously.

Usually, the heavy metal contamination seems not to be one important issue owing to the low metal contents in leachates for most of the sanitary landfills ${ }^{1}$. The other reason was that the trace metals in leachates were strongly reduced through adsorption and precipitation process under the anaerobic condition of the sanitary landfills ${ }^{2}$. However, because there were lack of the necessary decontamination facilities for the unsanitary landfills, especially the bottom and lateral linear ${ }^{3}$ and the unsanitary landfills were widely spread in rural areas of China ${ }^{4}$. Moreover, it was found that some of the landfills were surrounded by farmland, especially the paddy field. Since $\mathrm{Zn}$ and $\mathrm{Cd}$ in the solid waste mostly was found in reducible form and was more susceptible to be leached ${ }^{5}$. When the surface water was used as the irrigation water of the farmland, it was possible that the metals may be accumulated in the human body through the food chain after part of the metals was adsorbed by the soil ${ }^{6}$, then the agricultural ecosystem was under the threatening of metal contamination.

Rice is one of the dominant agricultural crops in China and in the world and the elevated rice metals may cause many debilitating diseases through the bioaccumulation effect of rice $^{7}$. Whereas, to our best of knowledge, there were little data available and few research reports about the contamination report of abandoned rural waste unsanitary landfills in China so far. The main aim of this work is (1) to understand the potential metal contamination in a soil-rice ecosystem in the vicinity of abandoned rural unsanitary landfill; (2) to determine the soil factors influencing the metal bioavailability in a soilrice system. This research would be helpful to provide useful information to agricultural management and environmental management for the abandoned rural unsanitary landfill. 


\section{EXPERIMENTAL}

Description of study area: Gaoqiao unsanitary landfill was one abandoned rural waste located in Qishan village, Ningbo city. The site was constructed in 1990s and closed in 2005 and mainly assumed the responsibility of disposing the farmers' daily waste. Its daily waste input, service population, land area and accumulated waste volume of the unsanitary landfill were 50 ton/day, 135000 people, $7500 \mathrm{~m}^{2}$ and 52500 $\mathrm{m}^{3}$, respectively.

Ningbo is located in the middle part of the coastline in southeast China (latitude of 28051' E 30o33' N) and is a classical subtropical monsoon climate region with an average annual precipitation of $1500 \mathrm{~mm}^{8}$. The city has a population of 6.9 million in 2007 and the rural land accounts for $74.9 \%$ of the total area in the region.

Sampling: During the period of maturity for rice (at the end of September, 2008), four pairs of rice (Oryza sativa L.) and soil samples with same location were collected in a distance of $0-120 \mathrm{~m}$ to the unsanitary landfill (Fig. 1). The reference $(\mathrm{CK})$ of soil and rice were sampled in the paddy field far from the unsanitary landfill. Each sample was the composite of 3 sub-samples within a distance of $0.5 \mathrm{~m}$ surrounding a specific sampling location. The rice samples included root, stem and leaf and rice grain. Soil samples, from 0-20 cm in depth, were collected at each sampling point and mixed thoroughly to get a representative sample of $1.5-2.0 \mathrm{~kg}$.

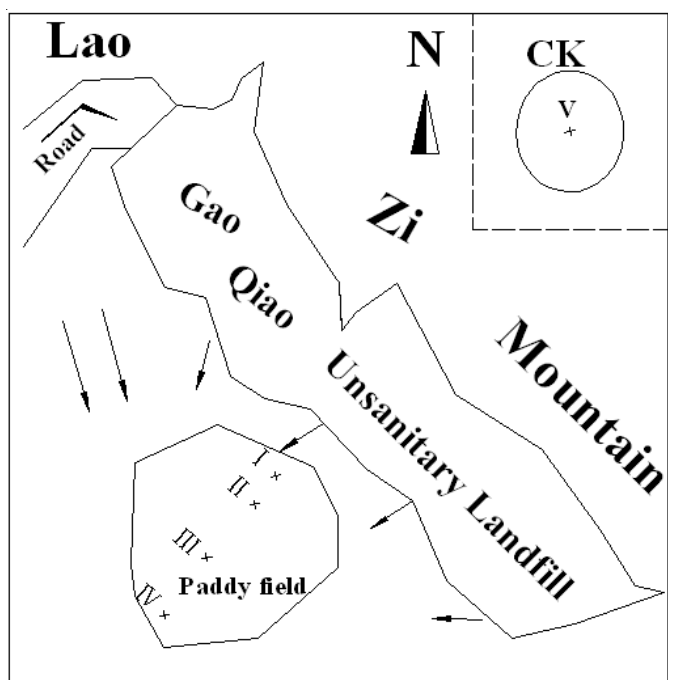

Fig. 1. Rural uncontrolled landfill in Gaoqiao. Note: X, sampling point of rice and soil. Arrow indicates the flow direction of the leachate

Sampling preparation and analysis: The soil samples were air dried in shady and cool conditions until a constant weight was reached. Then the soil samples were passed a 1 $\mathrm{mm}$ mesh sieve and the $\leq 1 \mathrm{~mm}$ fraction was collected. By quartering each soil sample, $c a$. 50-100 g samples were ground with a wood bar and sieved with $0.15 \mathrm{~mm}$ mesh to collect fine particles $(<0.15 \mathrm{~mm})$. The prepared soil and rice samples were sealed in polyethylene bags and stored at $4{ }^{\circ} \mathrm{C}$ for further analyses. The total nitrogen, $\mathrm{NH}_{4}-\mathrm{N}$, total phosphorus and organic matter $(\mathrm{OM})$ of the soil and solid waste were measured using standard procedures ${ }^{9}$. For heavy metal analysis of soil, $0.25 \mathrm{~g}$ soil was digested with $4 \mathrm{~mL} \mathrm{HNO}_{3}, 1 \mathrm{~mL} \mathrm{HF}$ and $1 \mathrm{~mL}$
$\mathrm{HClO}_{4}$ under sealed Teflon tank for $10 \mathrm{~h}$. The metal analysis of rice was conducted as following: the fresh rice was washed in tap water and rinsed with deionized water, then dried at $80{ }^{\circ} \mathrm{C}$ for $24 \mathrm{~h}$, grounded with agate mortar, digested with $\mathrm{HNO}_{3}: \mathrm{H}_{2} \mathrm{SO}_{4}: \mathrm{HC1O}_{4}(8 \mathrm{~mL}: 1 \mathrm{~mL}: 1 \mathrm{~mL})$ under sealed Teflon tank. The Heavy metals of soil and rice were measured using ICP-MS (Agilent 7500a). All the analyzed results were expressed on a dry weight basis.

Assessment method of soil contamination: Geoaccumulation index $\left(\mathrm{I}_{\mathrm{geo}}\right)$ was calculated to assess the degree of heavy metal pollution in soil surrounding the unsanitary landfills. $\mathrm{I}_{\text {geo }}$ was calculated by the following equation: $\mathrm{I}_{\text {geo }}=\log _{2}$ $\left[\mathrm{C}_{\mathrm{n}} / 1.5 \mathrm{~B}_{\mathrm{n}}\right]$, where $\mathrm{C}_{\mathrm{n}}$ represents the measured concentration of the metal $n$ and $B_{n}$ is the background values of the soils ${ }^{10,11}$. The background soil was collected from the paddy field far away (over $500 \mathrm{~m}$ ) from the Gaoqiao landfill and its background values were used as the reference values.

Data analysis: Student's $t$-test (comparison analysis of paired values) was used to compare the soil $\mathrm{pH}$ in the vicinity of landfill with that of CK. Pearson correlationship was use to measure the correlation between the observations. Data analysis and figure plot were carried out by using SPSS 14 and Origin 8 , respectively.

\section{RESULTS AND DISCUSSION}

Metal contents in soils and rice: Fig. $2 \mathrm{~A}$ illustrates the contamination of soils surrounding the unsanitary landfill. The results show the metal contents of soil were in the order of $\mathrm{Zn}$ $>\mathrm{Pb}>\mathrm{Cr}>\mathrm{Cu}>\mathrm{Cd}$ and their average values were $118.92 \pm$ $33.62,45.64 \pm 11.85,33.28 \pm 4.90,24.14 \pm 2.69,1.45 \pm 0.59$ $\mathrm{mg} / \mathrm{kg}$, respectively and they were $1.6,1.9,4.8,1.5$ and 1.6folds of CK. The average metal contents of soils were much higher than that of $\mathrm{CK}$, implying the obvious anthropogenic effect. The coefficient variation $(\mathrm{CV})$ of the five metals were $14.7,11.1,41.0,28.3$ and $26.0 \%$, respectively and the metal $\mathrm{CVs}$ did not show a great variability, indicating that the distribution of the trace metal in the sampling region were evenly. Compared with maximum allowable concentrations (MAC) (GB 15618-1995) of metals in agricultural soils in China, soil $\mathrm{Cd}$ contents were $2.29 \pm 0.37,0.72 \pm 0.15,1.55 \pm 0.12$ and $1.08 \pm 0.37 \mathrm{mg} / \mathrm{kg}$ at sampling points I, II, III and IV, respectively and were higher than maximum allowable concentration value. Soil $\mathrm{Zn}, \mathrm{Pb}, \mathrm{Cu}$ and $\mathrm{Cr}$ contents were all below the maximum allowable concentration levels.

The metal contents in rice root, rice stem-leaf and rice grain were given in Fig. 2B-2D. The metal contents of rice were ranked in the order of root $>$ stem-leaf $>$ grain. Chromium contents in rice root, rice stem-leaf and rice grain were 26.6, 8.7 and $4.0 \mathrm{mg} / \mathrm{kg}$, respectively and the CVs of corresponding rice organs were 68.6, 34.9 and $47.3 \%$; $\mathrm{Cu}$ contents in root, stem-leaf and grain were 40.1, 7.4 and $5.5 \mathrm{mg} / \mathrm{kg}$ and the CVs of corresponding rice organs were $38.8,17.8$ and $8.7 \%$; $\mathrm{Zn}$ contents in root, stem-leaf and grain were 84.5, 34.5 and 25.9 $\mathrm{mg} / \mathrm{kg}$ and the corresponding CVs were 27.4, 28.4 and $3.3 \%$; $\mathrm{Cd}$ contents in root, stem-leaf and grain were $1.33,0.12$ and $0.03 \mathrm{mg} / \mathrm{kg}$ and the corresponding CVs were 25.3, 30.0 and $53.6 \%$; $\mathrm{Pb}$ contents in root, stem-leaf and grain were 14.1, 1.2 and $0.2 \mathrm{mg} / \mathrm{kg}$, with the corresponding CVs, 31.6, 45.3 and $17.3 \%$, respectively. 
(A)
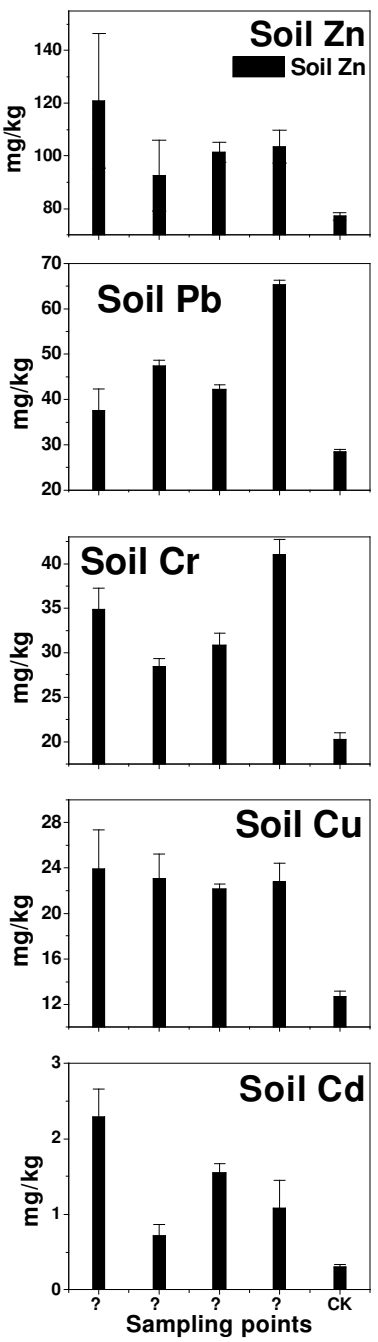

(B)
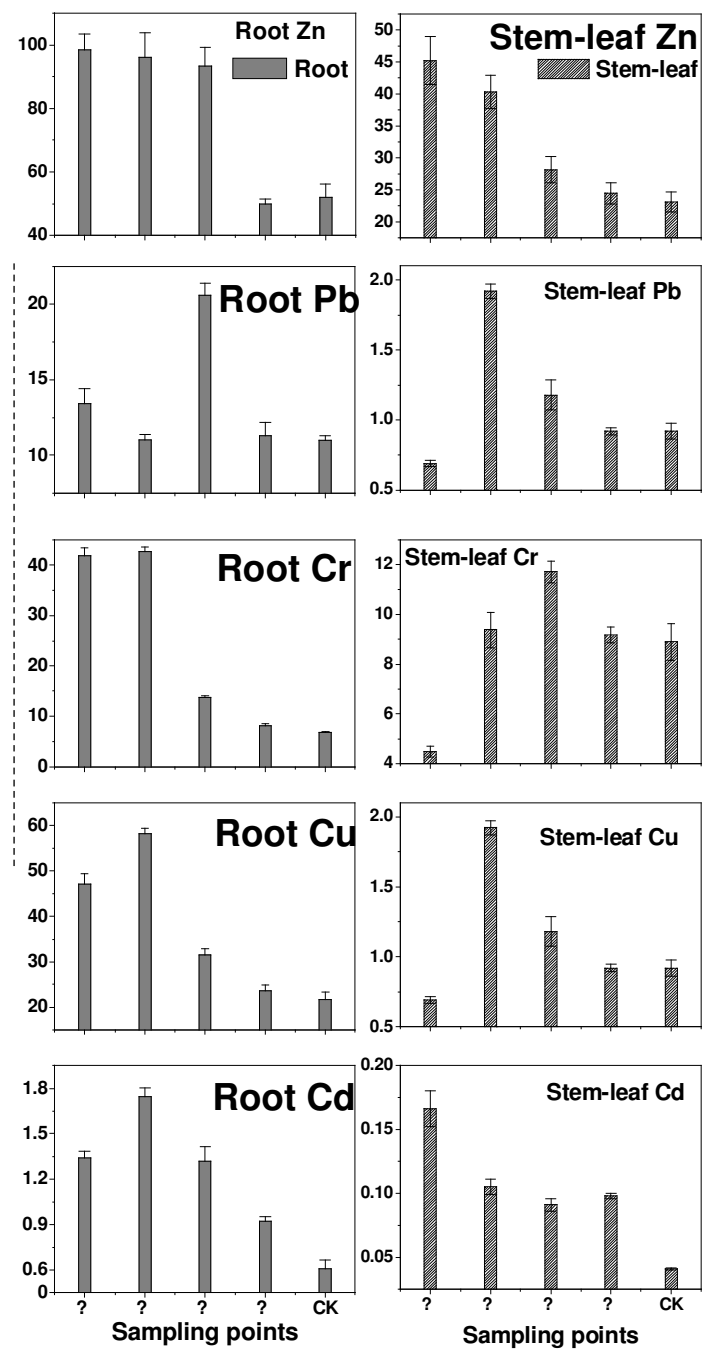

(D)
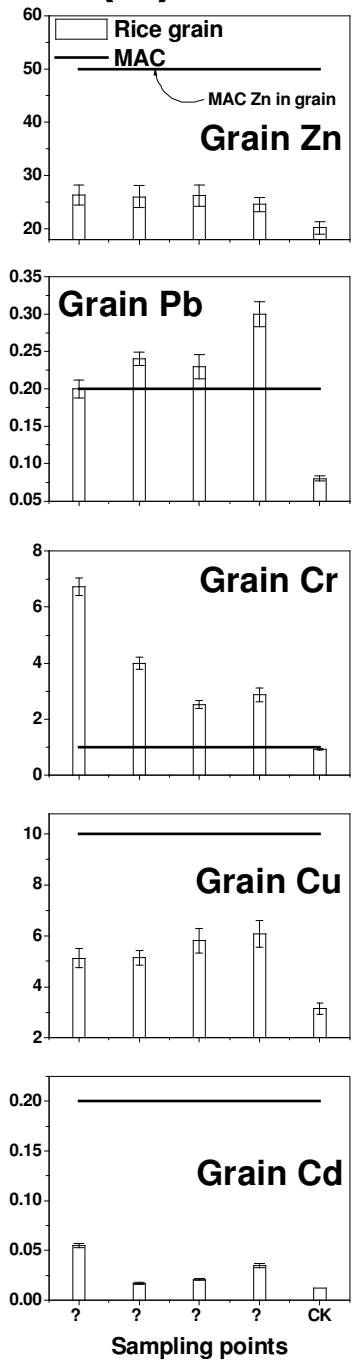

Fig. 2. Heavy metal contents in soil and rice surrounding the abandoned rural unsanitary landfill in Gaoqiao (A: soil; B: rice root; C, rice stem-leaf; D, rice grain). Note: maximum allowable concentration of soil $\mathrm{Zn}, \mathrm{Pb}, \mathrm{Cr}, \mathrm{Cu}$ and $\mathrm{Cd}$ were 200, 250, 250, 50 and $0.3 \mathrm{mg} / \mathrm{kg}$, respectively (GB 15618-1995) and the corresponding threshold values in rice grain were 50,0.2, 1, 10 and $0.2 \mathrm{mg} / \mathrm{kg}$, respectively (GB 2762-2005)

Contamination assessment of soil and rice: To describe the overall metal contents of soil and rice (including root, stem-leaf and grain) surrounding the unsanitary landfill, the arithmetic metal contents in different sampling points from the unsanitary landfill (Table-1) were used as the mean values. As shown in Table-1, the higher Igeo of $\mathrm{Cd}$ indicates that the soil was moderately polluted with $\mathrm{Cd}$ and were unpollutedmoderately with $\mathrm{Pb}, \mathrm{Cr}$ and $\mathrm{Cu}$ and the soil was not contaminated with $\mathrm{Zn}$ overall.

Fig. 2 shows that the average contents of rice root, stemleaf and grain were evidently higher than that of $\mathrm{CK}$, implying that there was clear metal accumulation trend in rice organs. The result means that the rice was very possibly contaminated with metals within the sampling region. To quantify the contamination degree, the grain metal contents were compared with the food thresholds (maximum allowable concentration) of rice. Here, the $\mathrm{Cr}$ and $\mathrm{Pb}$ contents in rice grain were much higher than the thresholds (especially $\mathrm{Cr}$ ) and their mean values were 2.9-6.7 folds and 1.0-1.5 folds of the thresholds, respectively (1.0 mg/kg for $\mathrm{Cr}$ and $0.2 \mathrm{mg} / \mathrm{kg}$ for $\mathrm{Pb}, \mathrm{GB} 2762-2005)$, while the $\mathrm{Cr}$ and $\mathrm{Pb}$ content of rice $\mathrm{CK}$ was 0.92 and $0.08 \mathrm{mg} /$ $\mathrm{kg}$, respectively, below the maximum allowable concentration

TABLE-1

HEAVY METALS IN SOIL IN THE VICINITY OF GAOQIAO UNSANITARY LANDFILL

\begin{tabular}{lccccc}
\hline & $\mathrm{Zn}(\mathrm{mg} / \mathrm{kg})$ & $\mathrm{Pb}(\mathrm{mg} / \mathrm{kg})$ & $\mathrm{Cr}(\mathrm{mg} / \mathrm{kg})$ & $\mathrm{Cu}(\mathrm{mg} / \mathrm{kg})$ & $\mathrm{Cd}(\mathrm{mg} / \mathrm{kg})$ \\
\hline Average $\pm \mathrm{SD}$ & $104.6 \pm 11.8$ & $48.1 \pm 12.1$ & $33.8 \pm 5.5$ & $23.0 \pm 0.7$ & $1.4 \pm 0.7$ \\
Range & $92.6-120.9$ & $37.5-65.3$ & $28.4-41.0$ & $22.1-23.9$ & $0.7-2.3$ \\
Reference & 77.1 & 28.4 & 20.23 & 12.69 & 0.3 \\
Igeo* & -0.15 & 0.14 & 0.14 & 0.27 & 1.52 \\
Soil MAC (GB 15618-1995) & 200 & 250 & 250 & 50 & 0.3 \\
\hline
\end{tabular}

*Igeo has no unit. 
level. The rice was the main staple in the southeast China (including Ningbo). Therefore, the long-term consumption of the rice with metal contamination could bear risk of heavy metal exposure to the consumers.

Factors affecting the metal accumulation in soil-rice ecosystem near the unsanitary landfill: Cadmium migration was active in soil-rice ecosystem and it was assumed that $\mathrm{Cd}$ was more susceptible to be released into the food chain and poses a potential threat to the human body ${ }^{12}$. The soil was moderately polluted with $\mathrm{Cd}$. However, there was one noteworthy phenomenon, i.e., in rice grain $\mathrm{Cd}$ was much lower than the thresholds.

In the normal $\mathrm{Cd}$ addition experiment, the bioavailabity of soil $\mathrm{Cd}$ was relatively high, since the $\mathrm{Cd}$ chemicals added were in the form of $\mathrm{Cd}\left(\mathrm{NO}_{3}\right)_{2}$ or $\mathrm{CdCl}_{2}$, etc. However, in our research, the leachate should be one of the main processes to transport $\mathrm{Cd}$ into soil. The soil $\mathrm{pH}$ and soil $\mathrm{Cd}$ were affected by the landfill condition and then affected the rice $\mathrm{Cd}$ content. The linear correlation analysis could be help to explain the question, which was listed on Table-2. Table-2 shows that the stem-leaf $\mathrm{Cd}$ was correlated with grain $\mathrm{Cd}$ and soil $\mathrm{pH}$ and grain Cd content was significantly $(p<0.05)$ correlated with soil $\mathrm{Cd}$. Soil $\mathrm{pH}$ generally was consider to have the significant effect on the rice grain ${ }^{6,13}$ and it was consistent with the result of Table- 2 .

\begin{tabular}{lcc}
\multicolumn{3}{c}{ TABLE-2 } \\
\multicolumn{3}{c}{ PEARSON CORRELATION COEFFICIENTS BETWEEN } \\
\multicolumn{3}{c}{ CD CONTENTS IN DIFFERENT RICE ORGANS WITH } \\
\multicolumn{3}{r}{ SOIL pH AND SOIL Cd CONTENTS $(\mathrm{n}=5)$} \\
\hline Roil pH & Soil Cd \\
\hline Root Cd & 0.244 & 0.614 \\
Stem-leaf Cd & 0.776 & $0.895^{*}$ \\
Grain Cd & $0.953^{* *}$ & $0.857^{*}$ \\
Soil Cd & 0.711 & - \\
\hline${ }^{* * * *}$ Denote significant level at $p<0.05$ and 0.01, respectively.
\end{tabular}

The soil $\mathrm{pH}$ in the vicinity of Gaoqiao landfill increased to 5.5-6.6, while the average $\mathrm{pH}$ of soil $\mathrm{CK}$ was 5.0. The result of a one-sample $t$-test shows that they had significant difference $(t=3.119, p=0.026)$ and suggests that the unsanitary landfill contributed noticeable effect on the soil $\mathrm{pH}$. The leachate entered the surface soil continuously under the precipitation and raised the soil $\mathrm{pH}$ due to the slightly alkaline characteristic of leachate ( $\mathrm{pH}$ between 7.3 and 8.3). On the other side, the soil organic mater, total nitrogen, total phosphorus and metal contents in the vicinity of Gaoqiao landfill increased gradually and were evidently higher than that of soil CK (Fig. 2), because the leachate contained a certain amount of organic matter, nutrients and trace elements and a part of these materials were adsorbed by the soil in the process of leachate flowing. Therefore, this resulted in the two interrelated factors affecting the metal uptake of rice: the higher soil $\mathrm{pH}$ would be helpful to increase the $\mathrm{Cd}$ absorption of rice, but the $\mathrm{Cd}$ uptake of rice would be hampered for the $\mathrm{Cd}$ bioavailability of rice would be lowered under higher soil $\mathrm{pH}^{14}$. In addition, the higher soil $\mathrm{Zn}$ and $\mathrm{P}$ would be reduce the uptake of rice $\mathrm{Cd}^{13}$.

\section{Conclusion}

The soil-rice ecosystem adjacent to the abandoned rural unsanitary landfill had been contaminated. The soil $\mathrm{Cd}$ was higher than the maximum allowable content of agricultural soil. Geoaccumulation index values of soil $\mathrm{Cd}$ suggests that the soil was moderately polluted with $\mathrm{Cd}$, while the soils were unpolluted-moderately overall by $\mathrm{Cr}, \mathrm{Cu}$ as well as $\mathrm{Pb}$. There was a remarkable bioaccumulation trend of heavy metals in the rice organs (rice root, stem-leaf and grain). The $\mathrm{Cr}$ and $\mathrm{Pb}$ contents in rice grain were, 2.9-6.7 folds and 1.0-1.5 folds of the threshold levels, , respectively and much higher than the legislation limits. The slightly alkaline leachate from the unsanitary landfill was one of the main factors causing the higher soil $\mathrm{pH}$ and then affecting the absorption of rice on the Cd.

\section{ACKNOWLEDGEMENTS}

This work was supported by Nanjing University of Information \& Technology (NJUIST, No. S8111028001), Undergraduate Teaching Quality Reform Project in 2012 in NJUIST (N1885012079, N1885012180) and Ningbo Science and Technology Bureau (2006C11003).

\section{REFERENCES}

1. T.H. Christensen, P. Kjeldsen, P.L. Bjerg, D.L. Jensen, J.B. Christensen, A. Baun, H.-J. Albrechtsen and G. Heron, Appl. Geochem., 16, 659 (2001).

2. P. Flyhammar, Sci. Total Environ., 198, 123 (1997).

3. H.J. Xie et al., J. Zhejiang Univ. Sci. A, 10, 439 (2009).

4. L. Ru-Xin, Environ. Manage. China (Chinese), 23 (2006).

5. T. Prechthai, P. Parkpian and C. Visvanathan, J. Hazard. Mater., 156, 86 (2008).

6. K.L. Zhao, X.M. Liu, J.M. Xu and H.M. Selim, J. Hazard. Mater., 181, 778 (2010).

7. J.J. Fu, Q.F. Zhou, J.M. Liu, W. Liu, T. Wang, Q.H. Zhang and G.B. Jiang, Chemosphere, 71, 1269 (2008).

8. NMSB (Ningbo Municipal Statistice Bureau) and SONBSN (Survey Office of the National Bureau of Statistice in Ningbo), Ningbo Statistical Yearbook 2006 (in Chinese), Beijing: China Statistics Press (2007).

9. S.D. Bao, Soil and Agricultural Chemistry Analysis, in Chinese, Beijing, China: Chinese Agricultural Press, edn. 3 (2000).

10. Y.Q. Ji, Y.C. Feng, J.H. Wu, T. Zhu, Z.P. Bai and C.Q. Duan, J. Environ. Sci., 20, 571 (2008).

11. W.G. Zhang, H. Feng, J.N. Chang, J.G. Qu, H.X. Xie and L.Z. Yu, Environ. Pollut., 157, 1533 (2009).

12. H.Z. Zhang, Y.M. Luo, H.B. Zhang, J. Song, J.Z. Xia and Q.G. Zhao, Acta Pedologica Sin., 47, 628 (2010).

13. M.B. Kirkham, Geoderma, 137, 19 (2006).

14. P. L., X.X. Wang, T.L. Zhang, D.M. Zhou and Y.Q. He, J. Environ. Sci., 20, 449 (2008). 